\title{
Coping and Social Support as Potential Moderators of the Relation Between Anxiety and Eating Disorder Symptomatology
}

\author{
Ellen E. Fitzsimmons ${ }^{a}$ and Anna M. Bardone-Cone ${ }^{a}$ \\ Ellen E. Fitzsimmons: ellen.fitzsimmons@unc.edu; Anna M. Bardone-Cone: bardonecone@unc.edu \\ aUniversity of North Carolina at Chapel Hill, Department of Psychology, CB\#3270-Davie Hall, \\ Chapel Hill, NC, 27599, United States
}

\section{Abstract}

Trait anxiety and eating disorder (ED) symptomatology are often thought to be inextricably linked. Because anxiety often precedes an ED, predicts poor outcome, and persists even after recovery from an $\mathrm{ED}$, it is important to examine whether certain factors have the ability to potentially attenuate anxiety's effect on eating pathology. In the current study, we examined two possible moderating factors: coping skills and social support. Participants were 96 females seen at one point for an ED at a Midwestern clinic, including 53 with a current ED diagnosis and 43 who no longer met criteria for an ED and who were at varying levels of recovery. Results revealed that emotion-oriented coping moderated the relation between anxiety and ED symptoms. Individuals who were high in trait anxiety and who reported low levels of emotion-oriented coping reported much lower levels of ED symptomatology than those with high trait anxiety and high emotionoriented coping. Contrary to our hypotheses, task-oriented coping, avoidance-oriented coping, and perceived social support (total, family, friend, and special person) did not emerge as moderators of the relation between trait anxiety and eating pathology. Results provide growing support that factors that interact with anxiety can lessen anxiety's effect on eating pathology. Implications for treatment and future directions are discussed.

\section{Keywords}

eating disorders; anxiety; coping; social support

\section{Introduction}

In many ways, anxiety and eating pathology are closely intertwined. For one, a large proportion of women diagnosed with anorexia nervosa (AN) and bulimia nervosa (BN) also present with comorbid anxiety disorders (Bulik, 1995); furthermore, symptoms of anxiety may be present in most individuals with eating pathology even when criteria for an anxiety disorder are not met (Kaye, Bulik, Thornton, Barbarich, Masters, \& Price Foundation Collaborative Group, 2004). Next, for the majority of individuals who present with such comorbidity, the anxiety disorder occurred first (e.g., Bulik, Sullivan, Fear, \& Joyce, 1997; Schwalberg, Barlow, Alger, \& Howard, 1992). Additionally, the presence of anxiety may be

(C) 2010 Elsevier Ltd. All rights reserved.

Correspondence concerning this article should be addressed to Anna M. Bardone-Cone, Tel.: +1 9199625989 ; fax: +1919 962 2537.

Publisher's Disclaimer: This is a PDF file of an unedited manuscript that has been accepted for publication. As a service to our customers we are providing this early version of the manuscript. The manuscript will undergo copyediting, typesetting, and review of the resulting proof before it is published in its final citable form. Please note that during the production process errors may be discovered which could affect the content, and all legal disclaimers that apply to the journal pertain. 
predictive of a poor outcome (i.e., individual still met criteria for an eating disorder diagnosis) (Fichter, Quadflieg, \& Hedlund, 2006), and such anxiety symptoms often remain after recovery from the eating disorder (e.g., Bardone-Cone et al., 2010; Wagner et al., 2006). Because symptoms of anxiety may precede an eating disorder, predict poor outcome, and persist even after an individual has recovered, it is important to identify factors that, in interaction with anxiety, are associated with low eating pathology. In this study, we examine how two potential moderators, coping and social support, interact with anxiety to predict a wide range of eating pathology in a sample with a history of an eating disorder and a wide range of current eating disorder symptoms.

\subsection{The Relation Between Anxiety and Eating Pathology}

Several studies have found elevated trait anxiety among those suffering from eating disorders (e.g., Ahrén-Moonga, Holmgren, von Knorring, \& af Klinteberg, 2008; Kaye et al., 2004; Mizes, 1988), with the emergence of symptoms of anxiety typically predating the onset of the eating disorder (e.g., Brewerton et al., 1995; Sihvola et al., 2009; Silberg \& Bulik, 2005). This raises the possibility of anxiety being one significant path toward the development of eating disorders. While this pattern of onset may simply reflect the natural course of the two disorders, it seems plausible that anxiety could be a precursor to the development of eating pathology. Pallister and Waller (2008) suggest that some forms of childhood anxiety play a role in eating disorder etiology. For example, anxiety over social evaluation has been associated with excessive concerns about eating, shape, and weight (Schwalberg et al., 1992), which are known factors in the etiologic chain toward eating disorders (Eisele, Hertsgaard, \& Light, 1986; Graber, Brooks-Gunn, Paikoff, \& Warren, 1994). Another way in which anxiety may contribute to eating pathology highlights the "mood intolerance" present among some individuals with eating disorders (Fairburn, Cooper, \& Shafran, 2003, p. 517). This inability to deal with emotions, including anxiety, puts them at risk for engaging in dysfunctional behavior, including binge eating, purging, and intense exercising, as attempts to modulate negative affect.

Anxiety is associated with the course of an eating disorder in other ways, too. For example, trait anxiety and obsessiveness have been found to be predictive of poor eating disorder outcomes (Fichter et al., 2006; Löwe et al., 2001; Råstam, Gillberg, \& Wentz, 2003). Furthermore, researchers interested in recovery have found mixed evidence regarding the persistence of anxiety among those recovered from an eating disorder (e.g., Toner, Garfinkel, \& Garner, 1988; Yackobovitch-Gavan et al., 2009). Some evidence supports the notion that those recovered from an eating disorder have lower levels of anxiety compared to active eating disorder cases; for example, one 10-year follow-up study of individuals with AN found that $40.0 \%$ of those with active AN had a current anxiety diagnosis compared with only $17.6 \%$ of the asymptomatic group (Halmi et al., 1991). On the other hand, many researchers have found that anxiety and anxiety disorders persist even after recovery from an eating disorder (e.g., Bardone-Cone et al., 2010; Wagner et al., 2006) and that the anxiety may reflect persistent psychological distress in regard to eating (Windauer, Lennerts, Talbot, Touyz, \& Beumont, 1993). On balance, there appears to be more support for levels of anxious pathology remaining at least somewhat elevated among those recovered from an eating disorder in comparison to healthy controls (e.g., Kaye et al., 2004).

If anxiety remains elevated among those with a history of eating pathology despite recovery, the risk for relapse may increase (Mitchell, Davis, \& Goff, 1985). This may especially be so for those who used disordered eating behaviors as a response to anxiety and/or for whom anxiety maintains concerns about weight and shape. Accordingly, points of intervention should focus on decreasing symptoms of anxiety or identifying whether certain factors that interact with anxiety can lessen anxiety's effect on eating pathology. In this paper, we focus 
on the latter route, examining two potential moderating factors of the relation between anxiety and eating pathology: coping skills and social support.

\subsection{Coping}

Does the relation between anxiety and eating disorder symptoms have something to do with individuals' coping styles? Coping is a multidimensional construct referring to the thoughts and behaviors that people engage in so as to manage, tolerate, or reduce internal or external demands that are appraised as exceeding an individual's resources (Lazarus \& Folkman, 1984). Broadly, task-oriented coping involves efforts aimed at solving the problem or altering the situation, emotion-oriented coping involves reactions that are self-oriented, such as emotional responses, self-preoccupation, and fantasizing, and avoidance-oriented coping describes activities and shifts in mental focus aimed at avoiding the stressful situation (Endler \& Parker, 1990). Other work supports Endler and Parker's (1990) division of coping skills into these three main categories (e.g., Cosway, Endler, Sadler \& Deary, 2000; Pearlin $\&$ Schooler, 1978).

Generally, task-oriented coping is seen as adaptive and is associated with lower levels of anxiety and depression (Troop, Holbrey, Trowler, \& Treasure, 1994), while emotion- and avoidance-oriented coping are viewed as maladaptive and tend to be associated with increased distress (Endler, Parker, \& Butcher, 1993; Hathaway \& McKinley, 1989; Shatford $\&$ Evans, 1986). There is substantial evidence that individuals with eating disorders or disordered eating tend to engage in more maladaptive coping (e.g., Ball \& Lee, 2000; Koff \& Sangani, 1997; Soukup, Beiler, \& Terrell, 1990; VanBoven \& Espelage, 2006), and emerging evidence that decreasing eating pathology is associated with more adaptive coping and less maladaptive coping (Bloks, Van Furth, Callewaert, \& Hoek, 2004; Fitzsimmons \& Bardone-Cone, in press). For example, Troop, Holbrey, and Treasure (1997) found that women with AN and BN utilized more cognitive avoidance (a type of avoidance-oriented coping) and more cognitive rumination (a type of emotion-oriented coping) than healthy controls. Further, in several studies using the Coping Inventory for Stressful Situations (CISS; Endler \& Parker, 1990 - the same measure utilized in the current study), researchers found that emotion-oriented coping was positively associated with both bulimic symptomatology (Janzen, Kelly, \& Saklofske, 1992) and disordered eating in general (Koff \& Sangani, 1996); Bekker and Boselie (2002) also found that women with eating disorder symptoms utilized more emotion-oriented coping than controls. Utilizing the Ways of Coping Questionnaire (WCQ; Folkman \& Lazarus, 1988), Ghaderi and Scott (2000) found that individuals with an eating disorder reported using more escape avoidance (i.e., wishful thinking and behavioral efforts to escape or avoid the problem), which is in line with much previous research (e.g., Ball \& Lee, 2000; Troop et al., 1994). Thus, we hypothesized that among those with elevated anxiety, healthy coping (i.e., increased use of task-oriented coping and decreased use of emotion- and avoidance-oriented coping) would be associated with less eating disorder symptomatology.

In their review, Pallister and Waller (2008) posit that Beck's cognitive model of anxiety disorders (Beck, Emery, \& Greenberg, 1985) may help to connect anxiety, coping, and disordered eating. According to Beck's theory, the central problem of anxiety involves one's assessment of fairly harmless situations and stimuli as excessively threatening, while at the same time, underestimating one's own ability to handle the situation or cope (Beck et al., 1985). It may be that many individuals with eating disorders are unable to manage their anxiety, due to their ineffectual coping practices, and instead turn to elements of disordered eating as a reaction to anxiety (e.g., binge eating to escape negative affect (Heatherton \& Baumeister, 1991), restrictive eating to regain a sense of control). Thus, the combination of anxiety and its dysregulation may lead to the development of eating disorder symptoms and may impede recovery (Yackobovitch-Gavan et al., 2009). Perhaps if individuals were able to 
respond to their anxiety through the use of adaptive coping strategies, a result would be decreased eating pathology.

\subsection{Social Support}

We also tested whether perceived social support moderates the relation between anxiety and eating disorder symptoms. Social support is the perception or experience that one is loved, cared for, esteemed, and valued by others and part of a social network of mutual assistance (Willis, 1991). Research suggests that although the actual amount of support women with eating disorders receive may be similar to that of healthy controls (Jacobson \& Robins, 1989), individuals with eating pathology are actually very dissatisfied with their support networks and perceive their social support as lacking (Grissett \& Norvell, 1992). Indeed, it is the perceived adequacy of support that is thought to have an effect on an individual's vulnerability to mental illness (Henderson, Byrne, \& Duncan-Jones, 1981). Research also indicates that the presence of close friendships and social adaptation may be predictive of recovery from an eating disorder (Keller, Herzog, Lavori, Bradburn, \& Mahoney, 1992; Steiger, Leung, \& Thibaudeau, 1993). Further, individuals who considered themselves to be recovered from an eating disorder for a minimum of one year tended to fall somewhere between individuals with an active eating disorder and healthy controls in terms of their social functioning (e.g., number of supports, satisfaction with support, social/leisure functioning) (Rorty, Yager, Buckwalter, \& Rossotto, 1999). In general, social support is well established as a protective factor for distress and psychopathology, as well as an aid to recovery from distress (Schwarzer \& Knoll, 2007). Thus, social support may be an important factor that impacts the relation between anxiety and eating pathology (Cattanach \& Rodin, 1988). Specifically, Cattanach and Rodin (1988) note that since social support is intended to diminish the impact of potential stressors and aid in adaptation, inadequate social support may be instrumental in perpetuating the cycle of an eating disorder. The implication of this is that those with elevated anxiety who perceive strong social support (including, presumably, friends and family one can turn to when anxious) may exhibit less eating pathology than those with low levels of social support. Indeed, Wonderlich-Tierney and Vander Wal (2010) found that the relationship between social anxiety and eating disorder symptomatology was significantly moderated in this manner by total, family, and friend forms of perceived social support in a non-clinical sample. The current study seeks to extend these findings to the case of more general, trait-like anxiety, using a sample with a history of frank eating disorders.

\subsection{The Current Study}

In the present study, we tested moderator models of the relation between trait anxiety and eating disorder symptomatology. First, we examined whether the relation between anxiety and eating disorder symptoms depended on coping style. We predicted that adaptive coping would interact with anxiety to predict lower levels of eating disorder symptoms, while maladaptive coping would interact with anxiety to predict higher levels of eating disorder symptoms. In particular, we predicted that the combination of high anxiety and high levels of task-oriented coping or low levels of emotion- or avoidance-oriented coping would be associated with lower levels of eating pathology. Second, we assessed whether the relation between anxiety and eating disorder symptoms depended on total, family, friend, and special person forms of perceived social support, predicting that those who had high levels of anxiety and reported high levels of support would display fewer eating disorder symptoms than those with high anxiety and less perceived social support. 


\section{Method}

\subsection{Participants and Recruitment}

Attempts were made to contact all current and former female eating disorder patients (ages 16 and older) seen at the University of Missouri Pediatric and Adolescent Specialty Clinic $(N=273)$ between 1996 and 2007. This clinic is a primary care and referral clinic specializing in the care of children and adolescents (ages 10-25 years) that has physicians with expertise in eating disorders. Of the 273 eating disorder patients, 96 (35.2\%) were successfully contacted and recruited. Fifty-five $(20.1 \%)$ of the 273 were contacted but did not participate due to other time commitments or lack of interest. Of the remaining patients, four $(1.5 \%)$ were deceased and 118 patients $(43.2 \%)$ could not be contacted due to absent or incorrect mailing addresses or inability to make phone contact. These rates are fairly comparable to those of other studies doing a follow-up of eating disorder patients over a range of about 10 years (Reas, Williamson, Martin, \& Zucker, 2000; Yackobovitch-Gavan et al., 2009). Additionally, results indicated that participants were not significantly different from non-participants on clinical variables such as eating disorder diagnoses or age or BMI at first clinic visit. In sum, of the 151 eating disorder patients we were able to contact, $63.6 \%$ participated; 53 had a current eating disorder diagnosis (17\% AN, 6\% BN, and 77\% Eating Disorder Not Otherwise Specified (EDNOS)) as identified with the Structured Clinical Interview for DSM-IV (SCID; First, Spitzer, Gibbon, \& Williams, 1995) ${ }^{1}$ and 43 no longer met criteria for an eating disorder per the SCID and were at varying levels of recovery. By including individuals with an active eating disorder as well as those recovering or recovered from an eating disorder, we sought to examine how anxiety and coping/social support would interact to predict a wide range of levels of eating pathology among those with a history of an eating disorder.

For all participants, current contact information was sought via patient records, public records such as whitepages.com, court records, and marriage records, and paid tracking searches. Eligible participants were mailed a cover letter that described the study and included the lead researcher's phone number for requesting more information or expressing interest in participating. Up to two mailings were sent out and if there was no response at that point, then attempts were made to contact the eligible participant via phone to describe the study and solicit participation.

\subsection{Study Procedures}

After providing written consent, all participants first completed a set of questionnaires and then, on a separate date, an interview, which included the SCID. (For participants under the age of 18, we obtained written assent from the minor and written consent from a parent). For the majority of the participants, the time between questionnaires and interview was within one week. The majority of participants completed the questionnaires $(53.1 \%)$ and interview $(70.4 \%)$ in person. Those who lived too far away to travel to the study site completed the questionnaires via mail and did a phone interview. Interviews were privately conducted by one of three extensively trained individuals who participated in over 50 hours of training videos, role plays, and discussions about interviewing. Participants were provided financial remuneration for their participation after completing the interview. All aspects of this study were approved by the university's institutional review board.

\footnotetext{
${ }^{1} \mathrm{~A}$ diagnosis of AN was given whether or not the amenorrhea criterion was met. Although return of menses is an important index of recovery, its use as a diagnostic criterion is problematic because it does not apply to boys or premenstrual girls, and it is not meaningful among women taking oral contraceptives. Other researchers have expressed these concerns (Couturier \& Lock, 2006; Roberto, Steinglass, Mayer, Attia, \& Walsh, 2008) and have not required the presence of amenorrhea for a diagnosis of AN (Kaye et al., 2004).
} 


\subsection{Measures}

2.3.1. Structured Clinical Interview for DSM-IV, Patient Edition (SCID; First et al., 1995)—The SCID, a widely used semi-structured interview that has well-established reliability and validity (Segal, Hersen, \& Van Hasselt, 1994), was used to determine lifetime and current eating disorders (AN, BN, and EDNOS). EDNOS cases were those that met the SCID's definition of EDNOS (e.g., subthreshold AN, subthreshold BN, regular use of inappropriate compensatory behaviors, and binge eating disorder). A random subset (5\%) of the audiotaped interviews was examined to assess inter-rater reliability, yielding absolute agreement (kappa $=1.00)$ for current AN, BN, and EDNOS.

\subsubsection{Spielberger State-Trait Anxiety Inventory, Trait Anxiety Scale (STAI; Spielberger, Gorsuch, \& Lushene, 1970)—Trait anxiety, which refers to the} "relatively stable individual differences in anxiety proneness" (Spielberger et al., 1970, p. 3), was assessed using the 20-item trait anxiety scale of the STAI (Spielberger et al., 1970). Participants responded to items about their general tendency to display anxiety (e.g., feel nervous or tense) using a 4-point Likert scale ranging from almost never to almost always. The STAI has been found to have good discriminant validity, and the trait anxiety scale has been found to have good test-retest reliability ( .97 - Metzger, 1976; .86 - Rule \& Traver, 1983). Construct validity is demonstrated by the fact that scores for the state anxiety scale items consistently vary in the face of different stressors, while the scores for the trait scale items do not (Hedberg, 1972). Further, the STAI trait anxiety scale has been found to correlate highly with other self-report measures of negative affectivity (Watson \& Clark, $1984)$ and to differentiate between individuals with and without anxiety disorders (Taylor, Koch, \& McNally, 1992). In the current study, alpha was .93.

\subsubsection{Coping Inventory for Stressful Situations (CISS; Endler \& Parker, 1990)}

-Coping was assessed with the CISS, a 48-item self-report measure that assesses participants' general coping style. Participants indicate how often they engage in various activities when faced with a stressful situation using a 5-point Likert scale ranging from not at all to very much. Three subscales are generated, assessing task-oriented, emotionoriented, and avoidance-oriented coping. Task-oriented coping is comprised of purposeful efforts aimed at solving the problem (e.g., scheduling my time better, listing my priorities, analyzing the problem before reacting). Emotion-oriented coping describes emotional reactions that are self-oriented. The aim of these reactions is to reduce stress but efforts are not always successful (e.g., worrying about what to do, blaming myself for getting into the situation, telling myself it will not happen again) (Endler \& Parker, 1990). Avoidanceoriented coping consists of activities and cognitive changes aimed at avoiding the stressful situation (e.g., window shopping, trying to sleep, going for a walk). The internal validity of the CISS is excellent in a variety of samples (i.e., from the high .80s to the low .90s) (Endler \& Parker, 1990, 1993) and convergent validity has been established with other coping measures (Endler \& Parker, 1990, 1993). Additionally, the CISS emotion-oriented scale, but not the task-oriented scale, correlates positively with a number of indices of psychopathology (Endler et al., 1993; Hathaway \& McKinley, 1989). In the current study, alphas were as follows: task-oriented (.89), emotion-oriented (.87), and avoidance-oriented (.75).

\subsubsection{Multidimensional Scale of Perceived Social Support (MSPSS; Zimet,} Dahlem, Zimet, \& Farley, 1988)-The MSPSS is a 12-item self-report inventory that measures perceived social support from family, friends, and special persons. Participants respond using a 7-point scale ranging from very strongly disagree to very strongly agree, in terms of various aspects of social support, such as having people who can help when needed. Previous work has found coefficient alphas from .91 to .94 (Cecil, Stanley, Carrion, \& 
Swann, 1995; Dahlem, Zimet, \& Walker, 1991). Negative correlations between scores on the MSPSS and both anxiety and depression scores provide evidence for its construct validity (Zimet et al., 1988). In the current study, alpha was . 93 for the total scale and .91, . 92 , and .95 for the family, friends, and special person subscales, respectively.

\subsubsection{Eating Attitudes Test-26 (EAT-26; Garner, Olmsted, Bohr, \& Garfinkel,} 1982)—Eating disorder symptoms were assessed with the EAT-26, one of the most widely used standardized measures of eating disorder attitudes and behaviors (Garner, 1993). The EAT-26 is a 26-item scale using a 6-point Likert scale ranging from never to always. Studies have found the measure to be effective as a screening measure, with a cutoff score of 20 indicating a probable eating disorder (King, 1989, 1991), and internal consistency ( $\alpha=.94)$ and test-retest reliability ( $r=.84$ ) have been demonstrated (Carter \& Moss, 1984). In the current study, a coefficient alpha of .93 was obtained.

\subsection{Analytic Strategy}

To test the hypothesized moderator models, hierarchical multiple regression was utilized in the prediction of eating disorder symptoms (EAT-26). In Step 1, trait anxiety and the moderator of interest (e.g., task-oriented coping) were entered as main effects. In Step 2, the two-way interaction of trait anxiety and the moderator (e.g., trait anxiety $\mathrm{x}$ task-oriented coping) was entered. Interaction terms were created by multiplying together the centered, continuous trait anxiety variable and the centered, continuous moderator as recommended by Frazier, Tix, and Barron (2004). The nature of the significant interactions was assessed via simple slope analyses (Aiken \& West, 1991).

\section{Results}

\subsection{Descriptive Statistics}

Participants ranged in age from 16 to 40 years $(M=23.64$ years, $S D=4.74)$, with most identifying themselves as Caucasian $(92.7 \%), 1.0 \%$ as Asian and $6.2 \%$ as biracial/biethnic. In terms of socio-economic status, participants' highest levels of parental education ranged from 11 to 21 years ( $M=16.64$ years, $S D=2.84$ ).

Means and standard deviations for the study variables and their correlations are presented in Table 1. Correlations were generally as expected based on the literature, including positive correlations between eating disorder symptoms and both anxiety and emotion-oriented coping and negative correlations between eating disorder symptoms and both task-oriented coping and perceived social support. The negative correlation between eating pathology and avoidance-oriented coping was unexpected given that avoidance coping tends to be elevated in samples with eating pathology (Ball \& Lee, 2000).

\subsection{Anxiety $x$ Coping Skills Interactions Predicting Eating Disorder Symptomatology}

Altogether, three hierarchical multiple regressions were performed involving the interaction of anxiety and coping skills in the prediction of eating disorder symptomatology, the results of which are displayed in Table 2 . The trait anxiety $\mathrm{x}$ emotion-oriented coping interaction was significant in predicting EAT-26 scores $(t(85)=2.53, p=.013)$, but the other two interaction terms were not. As depicted in Figure 1, those with high levels of anxiety who engaged in low levels of emotion-oriented coping had lower levels of eating pathology than those with high anxiety and high emotion-oriented coping, suggesting that low levels of emotion coping may buffer the effect of high anxiety on eating disorder symptoms. (High and low levels of the predictors were determined by one standard deviation above and below the mean, respectively.) Furthermore, simple slope analyses indicated that emotion-focused coping was significantly associated with eating disorder symptoms at high levels of anxiety 
(1 $S D$ above the mean), $\beta=.35, t(85)=2.29, p=.024$, but not at low levels of anxiety ( $1 S D$ below the mean), $\beta=-.06, t(85)=-.39, p=.699$.

\subsection{Anxiety $x$ Social Support Interaction Predicting Eating Disorder Symptomatology}

The four hierarchical multiple regressions testing the interaction of trait anxiety and perceived social support (total, family, friend, and special person) in the prediction of eating disorder symptomatology were not significant (see Table 3 ).

\section{Discussion}

In the present study, we examined how the relation between trait anxiety and eating disorder symptoms may vary depending on levels (high vs. low) of various coping strategies and perceived social support in a sample of individuals with a history of an eating disorder and a wide range of current eating disorder symptoms. Our hypothesis that coping skills would moderate this relation was partially supported. We found that emotion-oriented coping (but not task- or avoidance-oriented coping) moderated the relation between trait anxiety and eating disorder symptoms, as measured by the EAT-26. As expected, individuals who were high in anxiety and who did not self-report much use of emotion-oriented coping had significantly less eating disorder symptomatology than those with high anxiety and high levels of emotion-oriented coping. Given that emotion-oriented coping is characterized by strategies often including an element of blame and rumination (e.g., blaming myself for having gotten into the situation, wishing I could change how I felt), it is not surprising that the combination of high anxiety and the elevated use of this coping style was associated with heightened eating pathology. Among those with low levels of anxiety, levels of disordered eating did not depend on the amount (high or low) of emotion-oriented coping they engaged in.

The types of stressors reported by individuals with eating disorders appear to fall within the normal range of experience (Cattanach \& Rodin, 1988). Because of this, it seems likely that the ability to manage stress and anxiety effectively (i.e., via healthy coping skills and/or social support), more so than the presence of specific stressors, has something to do with the likelihood of developing an eating disorder and the maintenance of the disease. However, in the case of task-oriented coping, we did not find a moderating effect on eating disorder symptoms. Regarding this finding, it may be that the anxiety felt by many of our participants did not map on to specific problems (i.e., feeling anxious in a more general sense rather than feeling anxiety over a particular issue) that could be handled with the purposeful strategies represented on the CISS task-oriented scale. Therefore, task-oriented coping may not be the most effective buffer against more generalized, trait levels of anxiety. Indeed, Kariv and Heiman (2005) found that perceived stress about academics (i.e., a sort of gestalt of academic stress - not a "specific" stressor) was associated with reduced use of task-oriented skills, whereas objective and more focused stress, measured by number of class and study hours, prompted task-oriented coping. On the other hand, Wondelich-Tierney and Vander Wal (2010) found that task-oriented coping significantly moderated the relation between social anxiety and eating pathology. As such, future research should continue to investigate the relations between anxiety, task-oriented coping, and eating disorder symptoms.

While avoidance-oriented coping did not moderate the relation between trait anxiety and eating disorder symptoms, we did find a significant negative correlation between avoidance and eating pathology. In general, the literature has tended to associate avoidance-oriented coping with eating disorders (e.g., Ball \& Lee, 2000; García-Grau, Fusté, Miró, Saldaña, \& Bados, 2002; Koff \& Sangani, 1997), but other research has not (e.g., Bittinger \& Smith, 2003; Fitzsimmons \& Bardone-Cone, in press; Janzen et al., 1992; Nagata, Matsuyama, Kiriike, Iketani, \& Oshima, 2000; Wonderlich-Tierney \& Vander Wal, 2010). Of course, 
one must keep in mind that avoidant coping strategies are not always maladaptive (Lazarus, 1993). Perhaps what matters is the type of avoidance that is used. For example, it is possible that those with low levels of eating pathology were using more "adaptive" forms of avoidance and that these sorts of strategies are well-represented on the CISS (e.g., spending time with a special person, going for a walk, phoning a friend), while more maladaptive avoidance behaviors, such as drinking to forget the problem, are not explicitly included in this measure. Avoidance-oriented strategies can be effective in the short-term for reducing pain, stress, or anxiety. Another way to understand the negative correlation between avoidance and eating pathology is that the combination and temporal ordering of coping skills may be important in determining what is "maladaptive." For instance, it may actually be advantageous for an individual to initially and briefly use avoidance techniques followed by a more task-oriented strategy (e.g., go for a run (avoid) to clear one's head and then return home and engage in active problem-solving). Given mixed findings in the literature, future research should continue to assess the nature of the relation between these constructs.

Although Wonderlich-Tierney and Vander Wal (2010) found that total, family, friend, and special person forms of social support moderated the relation between social anxiety and eating pathology, none of the interactive findings involving perceived social support were significant in the current study. This different pattern of findings could be due to sampling differences (i.e., non-clinical undergraduate sample vs. sample with a history of treatment for an eating disorder) and the use of social anxiety vs. trait anxiety. Further, the Wonderlich-Tierney and Vander Wal (2010) sample were all between 18 and 20 years of age and first year students, whereas the current sample was between 16 and 40 with a mean age of about 24 years of age; it could be that social support as a moderator of the relation between anxiety and eating disorder symptoms is more important in younger individuals - in particular, in moments of transition like the start of college. Additionally, WonderlichTierney and Vander Wal (2010) posit that the effects of social support may at times be unclear due to the complex nature of relationships, which include not only support, but also various expectations. As such, social support is an important construct to carefully examine in future work addressing issues related to anxiety and eating disorder symptomatology.

This study contributes to the existing literature by expanding our understanding of the relation between anxiety and eating pathology using more complex models (i.e., moderator models) and well-established and validated measures. An additional strength was the recruitment strategy. By sampling from a facility other than an eating disorders clinic and by including both individuals with an active eating disorder and those at some level of recovery, we were able to examine a broad range of eating disorder severity, contributing to the generalizability of these results to those with a history of an eating disorder.

One limitation of the current study was that we were unable to contact a significant minority of individuals for a variety of reasons, which included last name changes after marriage and cellular phone numbers, which are not recorded in a public registry. While no significant differences were found between participants and non-participants on relevant eating disorder measures from clinic charts (e.g., diagnoses, BMI at start of treatment), the groups could have differed on other unmeasured constructs that may have introduced bias. Additional limitations include the reliance on self-report and the cross-sectional design, which did not allow for an examination of the dynamic and temporal relations among anxiety, coping, social support, and eating disorder symptoms. Finally, the current sample size precluded us from examining moderator models in groups with shared eating disorder symptom profiles (e.g., those with current BN or a history of BN). However, given Fairburn et al.'s (2003) "transdiagnostic" theory of eating disorders, which posits that shared, but distinctive, clinical features of eating disorders tend to be maintained by similar psychological processes, and the fact that migration across eating disorder diagnostic categories is common 
(e.g., Fairburn et al., 1995; Sullivan, Bulik, Fear, \& Pickering, 1998), it is arguably appropriate to examine how trait anxiety and coping/social support interact to predict a wide range of eating pathology. That said, future research should consider using large enough sample sizes in order to examine these moderator models in different eating disorder diagnoses.

One key future direction involves examining anxiety, coping, social support, and eating pathology in a longitudinal framework given that improvements in coping skills/social support and feelings of anxiety likely both contribute to and are a result of decreased eating pathology. It is likely that changes in coping style (e.g., decreased reliance on emotional coping) contribute to decreased eating pathology and if this is confirmed by prospective research, there would be significant clinical implications. For example, clinicians may be well-served to teach individuals with and recovering from an eating disorder certain coping skills as a means to manage their anxiety (e.g., teach strategies for reducing one's use of emotion-oriented coping), as results of this study provide some indication that engaging in low levels of emotion-oriented coping may have a buffering effect on eating pathology. As has been pointed out by previous research (e.g., Mussell, Binford, \& Fulkerson, 2000; Romano \& Hage, 2000), it may also be of use to help young girls and women develop protective, effective coping strategies in the context of eating disorder prevention programming so that disordered eating behaviors and attitudes (and other maladaptive coping strategies) are less likely to become the coping strategies of choice for managing anxiety and other stressors (Streigel-Moore \& Steiner-Adair, 1998).

Additionally, assessing the study constructs using an ecological momentary approach may shed light on the micro-relations between these variables and provide data indicating specific responses (e.g., turned to a friend for support) to in-the-moment anxiety. It may be important to examine other ways of measuring the study constructs, as well. For example, while the current study utilized a well-validated and widely used measure of coping skills, there are several other well-established measures of coping (e.g., Ways of Coping Questionnaire, Folkman \& Lazarus, 1988), which define the various facets of coping in slightly different ways and also warrant consideration. Finally, future research may also wish to examine other factors that may attenuate the effects of anxiety on eating disorder symptomatology. For example, previous research has indicated that self-efficacy may buffer the impact of various stressors (e.g., Jex \& Bliese, 1999). Future work may thus wish to examine whether self-efficacy works as a moderator of the anxiety-eating pathology relation, as well. Of note, individuals with high anxiety and low emotion coping still had EAT-26 scores around the cut-off for a probable eating disorder, suggesting the need for exploring additional moderators that would even more powerfully interact with anxiety to further reduce eating disorder symptoms. Furthermore, researchers and clinicians should strive to identify individuals for whom reducing anxiety will likely lead to decreased eating disorder pathology and for whom this approach is unlikely to work (i.e., anxiety is expected to remain elevated, perhaps because of a high genetic loading for anxiety), in which case buffering factors should be identified and bolstered.

\section{Conclusion}

In conclusion, emotion-oriented coping moderated the relation between trait anxiety and eating pathology. Our results suggest that low anxiety is associated with low levels of eating pathology regardless of the level of emotion-oriented coping, but that for those with heightened anxiety, low (but not high) use of emotion-oriented coping skills is associated with lower levels of eating disorder symptoms. Given that anxiety and eating disorders are so closely intertwined, it is heartening and therapeutically informative to find that some factors may have the ability to make this relation more tenuous. 


\section{References}

Ahrén-Moonga J, Holmgren S, von Knorring L, af Klinteberg B. Personality traits and self-injurious behaviour in patients with eating disorders. European Eating Disorders Review 2008;16:268-275. [PubMed: 18240124]

Aiken, LS.; West, SG. Multiple regression: Testing and interpreting interactions. Thousand Oaks, CA: Sage Publications; 1991.

Ball K, Lee C. Relationships between psychological stress, coping and disordered eating: A review. Psychology and Health 2000;14:1007-1035.

Bardone-Cone AM, Harney MB, Maldonado CR, Lawson MA, Robinson DP, Smith R, Tosh A. Defining recovery from an eating disorder: Conceptualization, validation, and examination of psychosocial functioning and psychiatric comorbidity. Behaviour Research and Therapy 2010;48:194-202. [PubMed: 19945094]

Beck, AT.; Emery, G.; Greenberg, R. Anxiety disorders and phobias: A cognitive perspective. New York: Basic Books; 1985.

Bekker MH, Boselie KA. Gender and stress: Is gender role stress? A re-examination of the relationship between feminine gender role stress and eating disorders. Stress and Health 2002;18:141-149.

Bittinger JN, Smith JE. Mediating and moderating effects of stress perception and situation type on coping responses in women with disordered eating. Eating Behaviors 2003;4:89-106. [PubMed: 15000990]

Bloks H, Van Furth EF, Callewaert I, Hoek HW. Coping strategies and recovery in patients with a severe eating disorder. Eating Disorders 2004;12:157-169. [PubMed: 16864314]

Brewerton T, Lydiard R, Herzog D, Brotman A, O’Neil P, Ballenger J. Comorbidity of Axis I psychiatric disorders in bulimia nervosa. Journal of Clinical Psychiatry 1995;56:77-80. [PubMed: 7852257]

Bulik CM. Anxiety disorders and eating disorders: A review of their relationship. New Zealand Journal of Psychology 1995;24:51-62.

Bulik CM, Sullivan PF, Fear JL, Joyce PR. Eating disorders and antecedent anxiety disorders: A controlled study. Acta Psychiatrica Scandinavica 1997;96:101-107. [PubMed: 9272193]

Carter PI, Moss RA. Screening for anorexia and bulimia nervosa in a college population: Problems and limitations. Addictive Behaviors 1984;9:417-419. [PubMed: 6598003]

Cattanach L, Rodin J. Psychosocial components of the stress process in bulimia. International Journal of Eating Disorders 1988;7:75-88.

Cecil H, Stanley MA, Carrion PG, Swann A. Psychometric properties of the MSPSS and NOS in psychiatric outpatients. Journal of Clinical Psychology 1995;51:593-602. [PubMed: 8801234]

Cosway R, Endler NS, Sadler AJ, Deary IJ. The Coping Inventory for Stressful Situations: Factorial structure and associations with personality traits and psychological health. Journal of Applied Biobehavioral Research 2000;5:121-143.

Couturier J, Lock J. What is recovery in adolescent anorexia nervosa? International Journal of Eating Disorders 2006;39:550-555. [PubMed: 16791851]

Dahlem NW, Zimet GD, Walker RR. The Multidimensional Scale of Perceived Social Support: A confirmation study. Journal of Clinical Psychology 1991;47:756-761. [PubMed: 1757578]

Eisele J, Hertsgaard D, Light HK. Factors related to eating disorders in young adolescent girls. Adolescence 1986;21:283-290. [PubMed: 3461694]

Endler, NS.; Parker, JDA. Coping inventory for stressful situations (CISS): Manual. Toronto, Canada: Multi-Health Systems; 1990.

Endler, NS.; Parker, JDA. The multidimensional assessment of coping: Concepts, issues, and measurement. In: Van Heck, GL.; Bonaiuto, P.; Deary, IJ.; Nowack, W., editors. Personality psychology in Europe. 4th ed.. Tilburg, Netherlands: Tilburg University Press; 1993. p. 309-319.

Endler NS, Parker JDA, Butcher JN. A factor analytic study of coping styles and the MMPI-2 content scales. Journal of Clinical Psychology 1993;49:523-527. [PubMed: 8408679]

Fairburn CG, Cooper Z, Shafran R. Cognitive behaviour therapy for eating disorders: A "transdiagnostic" theory and treatment. Behaviour Research and Therapy 2003;41:509-528. [PubMed: 12711261] 
Fairburn CG, Norman PA, Welch SL, O'Connor ME, Doll HA, Peveler RC. A prospective study of outcome in bulimia nervosa and the long-term effects of three psychological treatments. Archives of General Psychiatry 1995;52:304-312. [PubMed: 7702447]

Fichter MM, Quadflieg N, Hedlund S. Twelve-year course and outcome predictors of anorexia nervosa. International Journal of Eating Disorders 2006;39:87-100. [PubMed: 16231345]

First, MB.; Spitzer, RL.; Gibbon, M.; Williams, JB. Structured Clinical Interview for DSM-IV Axis I Disorders - Patient Edition (SCID-I/P, Version 2.0). New York, NY: New York State Psychiatric Institute; 1995.

Fitzsimmons EE, Bardone-Cone AM. Differences in coping across stages of recovery from an eating disorder. International Journal of Eating Disorders. (in press).

Folkman, S.; Lazarus, RS. Manual for the Ways of Coping Questionnaire. Palo Alto, CA: Consulting Psychologists Press; 1988.

Frazier PA, Tix AP, Barron KE. Testing moderator and mediator effects in counseling psychology research. Journal of Counseling Psychology 2004;51:115-134.

García-Grau E, Fusté A, Miró A, Saldaña C, Bados A. Coping style and disturbed eating attitudes in adolescent girls. International Journal of Eating Disorders 2002;32:116-120. [PubMed: 12183940]

Garner DM. Self-report measures for eating disorders. Current Contents: Social and Behavioral Sciences 1993;25:8.

Garner DM, Olmsted MP, Bohr Y, Garfinkel PE. The Eating Attitudes Test: Psychometric features and clinical correlates. Psychological Medicine 1982;12:871-878. [PubMed: 6961471]

Ghaderi A, Scott B. Coping in dieting and eating disorders: A population-based study. The Journal of Nervous and Mental Disease 2000;188:273-279. [PubMed: 10830564]

Graber JA, Brooks-Gunn J, Paikoff RL, Warren MP. Prediction of eating problems: An 8-year study of adolescent girls. Developmental Psychology 1994;30:823-834.

Grissett NI, Norvell NK. Perceived social support, social skills, and quality of relationships in bulimic women. Journal of Consulting and Clinical Psychology 1992;60:293-299. [PubMed: 1592960]

Halmi KA, Eckert E, Marchi P, Sampugnaro V, Apple R, Cohen J. Comorbidity of psychiatric diagnoses in anorexia nervosa. Archives of General Psychiatry 1991;48:712-718. [PubMed: 1883254]

Hathaway, SR.; McKinley, JC. Minnesota Multiphasic Personality Inventory-2. Minneapolis: University of Minnesota Press; 1989.

Heatherton TF, Baumeister RF. Binge eating as escape from self-awareness. Psychological Bulletin 1991;110:86-108. [PubMed: 1891520]

Hedberg AG. Review of State-Trait Anxiety Inventory. Professional Psychology 1972;3:389-390.

Henderson, S.; Byrne, DG.; Duncan-Jones, P. Neurosis and the social environment. Sydney: Academic Press; 1981.

Jacobson R, Robins CJ. Social dependency and social support in bulimic and nonbulimic women. International Journal of Eating Disorders 1989;8:665-670.

Janzen BL, Kelly IW, Saklofske DH. Bulimic symptomatology and coping in a nonclinical sample. Perceptual and Motor Skills 1992;75:395-399. [PubMed: 1408596]

Jex SM, Bliese PD. Efficacy beliefs as a moderator of the impact of work-related stressors: A multilevel study. Journal of Applied Psychology 1999;84:349-361. [PubMed: 10380416]

Kariv D, Heiman T. Task-oriented versus emotion-oriented coping strategies: The case of college students. College Student Journal 2005;39:72-84.

Kaye WH, Bulik CM, Thornton L, Barbarich N, Masters K. Price Foundation Collaborative Group. Comorbidity of anxiety disorders with anorexia and bulimia nervosa. American Journal of Psychiatry 2004;161:2215-2221. [PubMed: 15569892]

Keller MB, Herzog DB, Lavori PW, Bradburn IS, Mahoney EM. The naturalistic history of bulimia nervosa: Extraordinarily high rates of chronicity, relapse, recurrence, and psychosocial morbidity. International Journal of Eating Disorders 1992;12:1-9.

King MB. Eating disorders in general practice population: Prevalence, characteristics and follow-up at 12 to 18 months. Psychological Medicine 1989 Monograph Suppl. 14:1-34. [PubMed: 2657828] 
King MB. The natural history of eating pathology in attenders to primary medical care. International Journal of Eating Disorders 1991;10:379-387.

Koff E, Sangani P. Effects of coping style and negative body image on eating disturbance. International Journal of Eating Disorders 1997;22:51-56. [PubMed: 9140735]

Lazarus RS. Coping theory and research: Past, present, and future. Psychosomatic Medicine 1993;55:234-247. [PubMed: 8346332]

Lazarus, RS.; Folkman, S. Stress, appraisal and coping. New York: Springer; 1984.

Löwe B, Zipfel S, Buchholz C, Dupont Y, Reas DL, Herzog W. Long-term outcome of anorexia nervosa in a prospective 21-year follow-up study. Psychological Medicine 2001;31:881-890. [PubMed: 11459385]

Metzger RL. A reliability and validity study of the State-Trait Anxiety Inventory. Journal of Clinical Psychology 1976;32:276-278.

Mitchell JE, Davis L, Goff G. The process of relapse in patients with bulimia. International Journal of Eating Disorders 1985;4:457-463.

Mizes JS. Personality characteristics of bulimic and non-eating-disordered female controls: A cognitive behavioral perspective. International Journal of Eating Disorders 1988;7:541-550.

Mussell MP, Binford RB, Fulkerson JA. Eating disorders: Summary of risk factors, prevention programming, and prevention research. The Counseling Psychologist 2000;28:764-796.

Nagata T, Matsuyama M, Kiriike N, Iketani T, Oshima J. Stress coping strategy in Japanese patients with eating disorders: Relationship with bulimic and impulsive behaviors. Journal of Nervous and Mental Disease 2000;188:280-286. [PubMed: 10830565]

Pallister E, Waller G. Anxiety in the eating disorders: Understanding the overlap. Clinical Psychology Review 2008;28:366-386. [PubMed: 17707562]

Pearlin LI, Schooler C. The structure of coping. Journal of Health and Social Behavior 1978;19:2-21. [PubMed: 649936]

Råstam M, Gillberg C, Wentz E. Outcome of teenage-onset anorexia nervosa in a Swedish community-based sample. European Child \& Adolescent Psychiatry 2003;12:78-90.

Reas DL, Williamson DA, Martin CK, Zucker NL. Duration of illness predicts outcome for bulimia nervosa: A long-term follow-up study. International Journal of Eating Disorders 2000;27:428-434. [PubMed: 10744849]

Roberto CA, Steinglass J, Mayer LES, Attia E, Walsh BT. The clinical significance of amenorrhea as a diagnostic criterion of anorexia nervosa. International Journal of Eating Disorders 2008;41:559563. [PubMed: 18454485]

Romano JL, Hage SM. Prevention and counseling psychology: Revitalizing commitments for the 21st century. The Counseling Psychologist 2000;28:733-763.

Rorty M, Yager J, Buckwalter JG, Rossotto E. Social support, social adjustment, and recovery status in bulimia nervosa. International Journal of Eating Disorders 1999;26:1-12. [PubMed: 10349578]

Rule WR, Traver MD. Test-retest reliabilities of the State-Trait Anxiety Inventory in a stressful social analogue situation. Journal of Personality Assessment 1983;47:276-277. [PubMed: 6886960]

Schwalberg M, Barlow D, Alger S, Howard L. Comparison of bulimics, obese binge eaters, social phobics and individuals with panic disorder on co-morbidity across DSM-III-R anxiety disorders. Journal of Abnormal Psychology 1992;101:4675-4681.

Schwarzer R, Knoll N. Functional roles of social support within the stress and coping process: A theoretical and empirical overview. International Journal of Psychology 2007;42:243-252.

Segal DL, Hersen M, Van Hasselt VB. Reliability of the Structured Clinical Interview for DSM-III-R: An evaluative review. Comprehensive Psychiatry 1994;35:316-327. [PubMed: 7956189]

Shatford LA, Evans DR. Bulimia as a manifestation of the stress process: A LISREL causal modeling analysis. International Journal of Eating Disorders 1986;5:451-473.

Sihvola E, Keski-Rahkonen A, Dick DM, Hoek HW, Raevuori A, Rose RJ, Kaprio J. Prospective associations of early-onset Axis I disorders with developing eating disorders. Comprehensive Psychiatry 2009;50:20-25. [PubMed: 19059509] 
Silberg JL, Bulik CM. The developmental association between eating disorders symptoms and symptoms of depression and anxiety in juvenile twin girls. Journal of Child Psychology and Psychiatry 2005;46:1317-1326. [PubMed: 16313432]

Soukup VM, Beiler ME, Terrell F. Stress, coping style, and problem solving ability among eatingdisordered inpatients. Journal of Clinical Psychology 1990;46:592-599. [PubMed: 2246365]

Spielberger, CD.; Gorsuch, RL.; Lushene, RE. STAI manual for the State-Trait Anxiety Inventory. Palo Alto, CA: Consulting Psychologists Press; 1970.

Steiger H, Leung F, Thibaudeau J. Prognostic value of pretreatment social adaptation in bulimia nervosa. International Journal of Eating Disorders 1993;14:269-276. [PubMed: 8275063]

Striegel-Moore, RH.; Steiner-Adair, C. Primary prevention of eating disorders: Further considerations from a feminist perspective. In: Vandereycken, W.; Noordenbos, G., editors. The prevention of eating disorders. New York: New York University Press; 1998. p. 1-23.

Sullivan PF, Bulik CM, Fear JL, Pickering A. Outcome of anorexia nervosa: A case-control study. American Journal of Psychiatry 1998;155:939-946. [PubMed: 9659861]

Taylor S, Koch WJ, McNally RJ. How does anxiety sensitivity vary across the anxiety disorders? Journal of Anxiety Disorders 1992;6:249-259.

Toner BB, Garfinkel PE, Garner DM. Affective and anxiety disorders in the long-term follow-up of anorexia nervosa. International Journal of Psychiatry in Medicine 1988;18:357-364. [PubMed: 3235281]

Troop NA, Holbrey A, Treasure JL. Stress, coping, and crisis support in eating disorders. International Journal of Eating Disorders 1998;24:157-166. [PubMed: 9697014]

Troop NA, Holbrey A, Trowler R, Treasure JL. Ways of coping in women with eating disorders. Journal of Nervous and Mental Disease 1994;182:535-540. [PubMed: 7931199]

VanBoven AM, Espelage DL. Depressive symptoms, coping strategies, and disordered eating among college women. Journal of Counseling and Development 2006;84:341-348.

Wagner A, Barbarich-Marsteller NC, Frank GK, Bailer UF, Wonderlich SA, Crosby RD, Kaye WH. Personality traits after recovery from eating disorders: Do subtypes differ? International Journal of Eating Disorders 2006;39:276-284. [PubMed: 16528697]

Watson D, Clark LA. Negative affectivity: The disposition to experience aversive emotional affects. Psychological Bulletin 1984;55:465-490. [PubMed: 6393179]

Willis, TA. Social support and interpersonal relationships. In: Clark, MS., editor. Prosocial behavior. Newbury Park, CA: Sage; 1991. p. 265-289.

Windauer U, Lennerts W, Talbot P, Touyz SW, Beumont PJV. How well are 'cured' anorexia nervosa patients? An investigation of 16 weight-recovered anorexic patients. British Journal of Psychiatry 1993;163:195-200. [PubMed: 8075911]

Wonderlich-Tierney AL, Vander Wal JS. The effects of social support and coping on the relationship between social anxiety and eating disorders. Eating Behaviors 2010;11:85-91. [PubMed: 20188291]

Yackobovitch-Gavan M, Golan M, Valevski A, Kreitler S, Bachar E, Lieblich A, Stein D. An integrative quantitative model of factors influencing the course of anorexia nervosa over time. International Journal of Eating Disorders 2009;42:306-317. [PubMed: 19040269]

Zimet GD, Dahlem NW, Zimet SG, Farley GK. The Multidimensional Scale of Perceived Social Support. Journal of Personality Assessment 1988;52:30-41. 


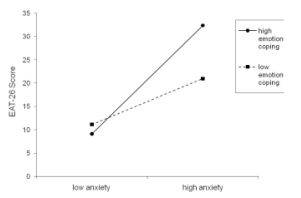

Figure 1.

The interaction of trait anxiety and emotion-oriented coping with EAT-26 scores as the dependent variable. 


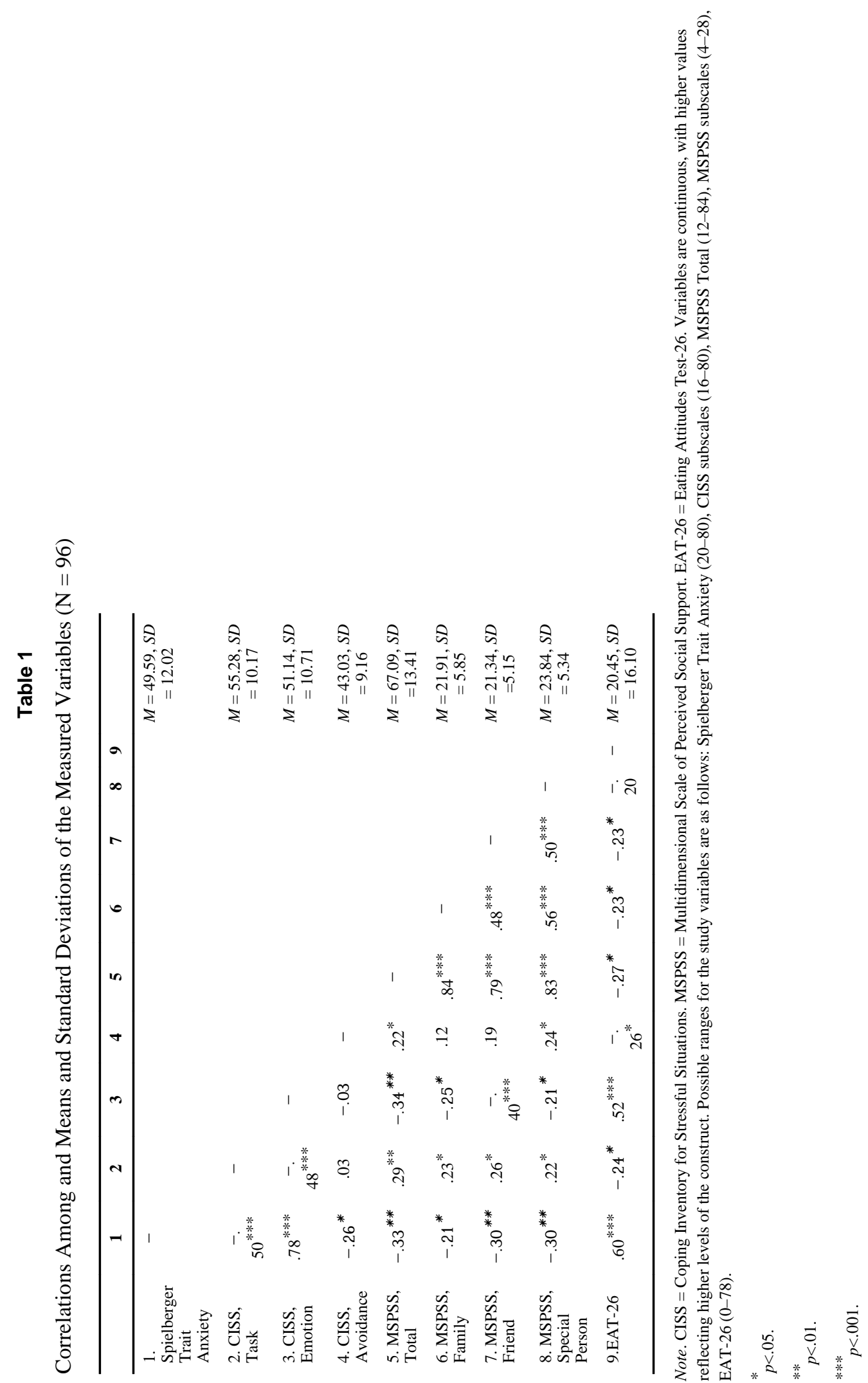




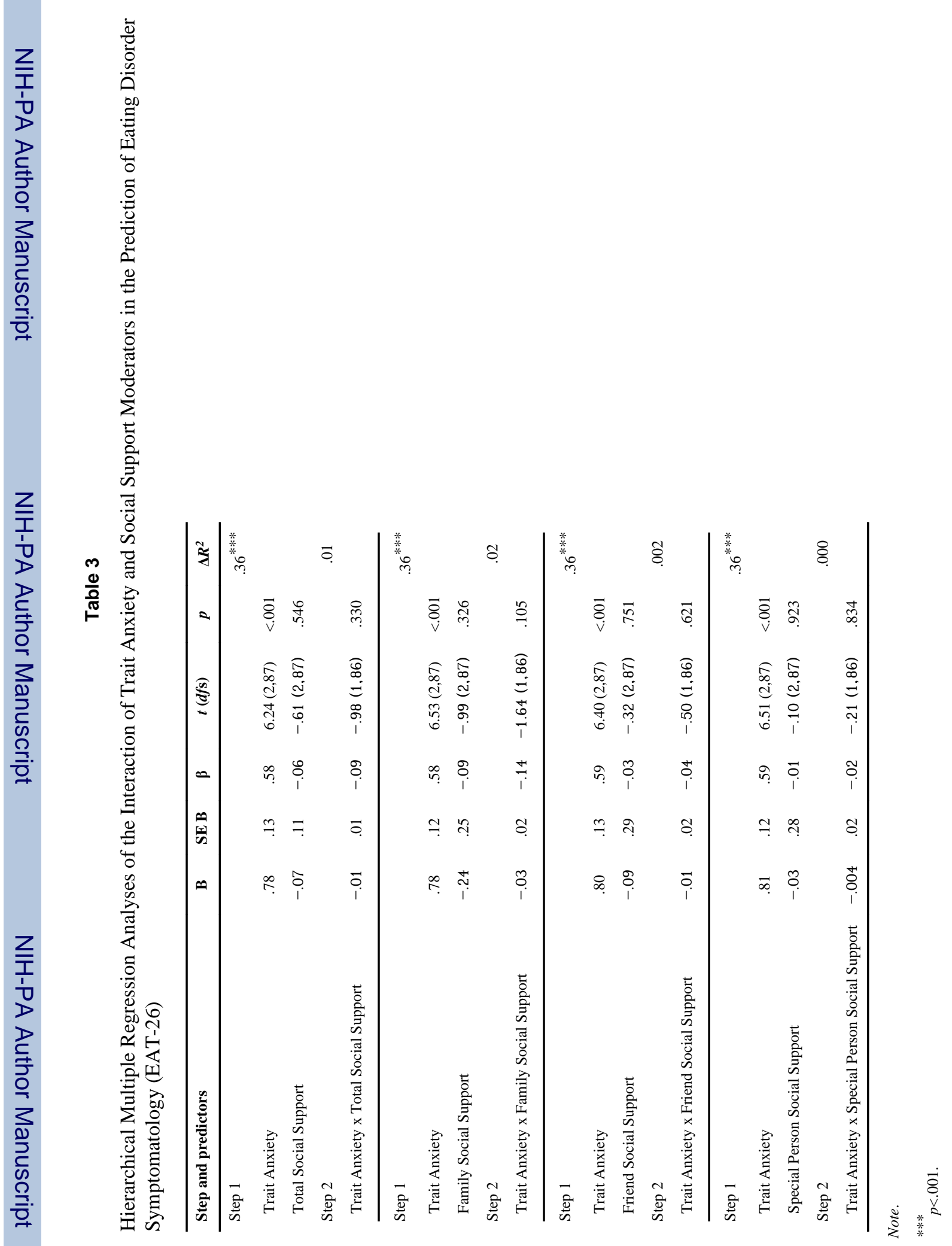

